\title{
An experimental investigation of mechanisms involved in bed load sheet production and migration
}

\author{
A. Recking, ${ }^{1}$ P. Frey, ${ }^{1}$ A. Paquier, ${ }^{2}$ and P. Belleudy ${ }^{3}$ \\ Received 24 January 2009; revised 24 April 2009; accepted 20 May 2009; published 19 August 2009.
}

[1] Field measurements indicate that, in gravel bed rivers, bed load may not be a one-toone response to shear stress but may instead fluctuate a great deal over time for a given flow condition. Both in flume and field experiments, these fluctuations were often associated with migration of low-relief bed forms called bed load sheets. Whereas several studies have described bed load sheets as a consequence of grain sorting, little is known about the mechanisms responsible for their production and migration. These were investigated in flume experiments. A set of 20 experiments was conducted under constant feeding rate conditions, with mixtures of different uniform sediments and for slopes varying from 0.8 to $9 \%$. Except for runs performed in high flow conditions, we observed periodic bed load sheet production and migration associated with fluctuations of bed slope, bed state (bed fining and paving), and bed load. Observations allowed us to conclude that bed load sheets resulted from very efficient vertical and longitudinal grain sorting that produced periodic local bed aggradation and erosion clearly observed in the upstream section of the flume. Fractional transport rates were measured in one run.

Combined with the results of experiments previously conducted by authors with uniform sediments, this experiment showed that the highest (peak) solid discharges were essentially caused by the much greater mobility of the coarser gravels when transported within bed load sheets. A scenario is proposed for the mechanisms involved in bed load sheet production and migration.

Citation: Recking, A., P. Frey, A. Paquier, and P. Belleudy (2009), An experimental investigation of mechanisms involved in bed load sheet production and migration, J. Geophys. Res., 114, F03010, doi:10.1029/2008JF000990.

\section{Introduction}

[2] Flume and field measurements indicate that, even in quasi-steady flow conditions, bed load transport fluctuates a great deal over time [Gomez et al., 1989; Hoey, 1992; Kuhnle, 1996]. This phenomenon was identified during the 1930s [Ehrenberger, 1931; Einstein, 1937; Mühlofer, 1933] and observations have increased in recent decades. Although fluctuations are clearly associated with dune migration in some cases [Blom et al., 2003; Blom et al., 2008; Dinehart, 1989; Emmett, 1975; Gomez et al., 1989], bed load fluctuations have also been observed with no noticeable bed forms and under quasi-steady flow conditions, both for transportation of gravels in the field [Bunte, 1992; Cudden and Hoey, 2003; Garcia et al., 2000; Gomez, 1983; Habersack et al., 2001; Jackson and Beschta, 1982; Kuhnle et al., 1989; Lekach and Schick, 1983; Madej and Ozaki, 1996; Meade, 1985; Paige and Hickin, 2000; Reid et al., 1985; Tacconi and Billi, 1987; Whiting et al., 1988] and

\footnotetext{
${ }^{1}$ UR Erosion Torrentielle Neige Avalanches, Cemagref, Saint Martin d'Hères, France.

${ }^{2}$ Hydrology Hydraulics Unit, Cemagref, Lyon, France.

${ }^{3}$ Laboratoire d'Étude des Transferts en Hydrologie et Environnement, UMR5564, CNRS, Grenoble, France.

Copyright 2009 by the American Geophysical Union. 0148-0227/09/2008JF000990
}

in flume experiments [Ancey et al., 2006, 2008; Böhm et al., 2006; Frey et al., 2003a; Hubbell, 1987; Iseya and Ikeda, 1987; Kuhnle and Southard, 1988; Suzuki et al., 1998].

[3] Bed load transport fluctuations in gravel bed rivers have often been associated with bed load sheet migration [Ashmore, 1991; Bennett and Bridge, 1995; Kuhnle and Southard, 1988; Whiting et al., 1988; Wilcock, 1992]. Bed load sheets are highly mobile and very low-relief bed forms, a few grain diameters thick and several centimeters to several meters long (depending upon the scale of the flow and/or of the channel), which differ from dunes by their height-to-length ratio: 1:10 instead of 1:3 [Whiting et al., 1988]. Whiting et al. [1988] considered that the low topographic slope, the height of bed load sheets and the short saltation distances of particles exclude the usual mechanisms proposed for the development of finite amplitude bed forms such as ripples and dunes. Instead, bed load sheets have been shown experimentally to result from interactions between the coarse and the fine fractions during bed load transport [Dietrich et al., 1989] and may exist only in moderate to poorly sorted sediments [Ikeda and Iseya, 1988]. Bed load sheets have been observed for a wide range of flow conditions, from $0.15 \%$ [Whiting et al., 1988] to 15\% slope [Billi et al., 1998; Frey et al., 2003b], with unimodal [Kuhnle and Southard, 1988] or bimodal natural sediment mixtures [Iseya and Ikeda, 1987], and in both straight and braided channels [Ashmore, 1988; Griffiths, 
1979; Hoey and Sutherland, 1991; Kang, 1982]. Bed load sheet migration has been observed to be associated with a peak solid discharge of the coarser gravel present in the sediment mixture, which has been attributed to greater mobility of coarse gravel transport over smooth bed areas within bed load sheets [Iseya and Ikeda, 1987; Whiting et al., 1988] or to the bed load sheet impacting sediments at rest on their front side [Kuhnle and Southard, 1988]. The amplitude of corresponding bed load transport variations (the ratio of maximum to minimum variations) is usually high and can attain a factor up to ten [Hoey and Sutherland, 1991; Iseya and Ikeda, 1987; Kuhnle and Southard, 1988]. Another major characteristic found in nearly all these studies is that bed load sheets appeared to occur in a periodic manner over a wide range of time scales, with several periods sometimes observed for a given flow condition [Kuhnle and Southard, 1988].

[4] Whereas bed load sheets have been recognized in many studies to originate upstream, to be the consequence of grain sorting and responsible for gravel peak solid discharge, little is known about the mechanisms involved in their production and migration, despite several attempts to derive theoretical models [Seminara et al., 1996]. Accordingly, the objectives of this paper were to (1) elucidate how grain sorting generates a bed load sheet and (2) investigate the mechanisms involved in bed load sheet migration and associated peak solid discharge (gravel transport efficiency versus impact effect). This was achieved through new flume experiments demonstrating the relations between bed load and local bed topography changes (slope fluctuation), and fractional measurement of bed load transport (using image analysis). Our overall research was conducted in two steps. The first step consisted in studying 143 bed load flow conditions at transport equilibrium with four uniform sediments on slopes ranging from 1 to 9\% [Recking et al., 2008a]. With additional data from the literature, the results were analyzed to yield new friction and bed load equations [Recking et al., 2008b], taken as a reference for uniform sediment bed load transport with no grain sorting. In the second step (this paper) the same experimental setup was used to study bed load transport of essentially bimodal mixtures composed of the previously analyzed uniform sediments. First the experimental arrangements and methods are presented. Then the experimental results conducted with sediment mixtures are presented, analyzed and discussed.

\section{Material and Methods}

\subsection{Experimental Arrangement}

[5] All experiments were conducted in the Lyon LMFA laboratory (Laboratoire de Mécanique des Fluides et d'Acoustique). The experimental arrangement was presented by Recking et al. [2008a] and consisted of an 8-mlong tilting flume (slope varying from 0 to $10 \%$ ). The flume width was adapted to each run (between 0.05 and $0.15 \mathrm{~m}$ ) in order to satisfy the two following conditions: (1) avoiding divagations and (2) keeping a width-to-depth ratio $W / H$ higher than 3.5 to ensure a fairly two-dimensional flow [Song et al., 1995]. Since the purpose of this experiment was to investigate fluctuations associated with transport mechanisms, it was very important to ensure constant feeding (both for fluids and solids). The water discharge was supplied from a constant head reservoir and controlled by an electromagnetic flowmeter. A customized sediment feeding system was specifically developed using a feeding tank and a conveyor belt, the velocity of which allowed us to control the sediment discharge. The stability of the conveyor belt was controlled during all experiments by recording the belt velocity using a special tachometer device. This feeding system was tested with several mixtures of uniform materials. All measurements indicated that no sorting effects occurred inside the tank, with the average solid discharge for each class remaining constant [Recking, 2006].

[6] Different sediment mixtures were obtained by mixing uniform materials of a median diameter of $2.3 \mathrm{~mm}, 4.9 \mathrm{~mm}$, and $9 \mathrm{~mm}$ (the $D_{84} / D_{16}$ ratio was, respectively, $1.15,1.22$, and 1.25 for each material; the grain size distribution curves are presented by Recking et al. [2008a]). Bimodal mixtures were preferentially used to facilitate observations and to be representative of natural gravel bed sediments [Kuhnle, 1996; Parker, 1991; Van den Berg, 1995]. Sediments were mixed by hand to avoid segregation, and mixtures collected at the flume outlet were stored, tested by sieving and readjusted to the initial distribution if necessary.

[7] There was no recirculation of either solids or liquids. This choice was imposed by the study's objectives: understanding the bed response immediately downstream of a cross section for a given constant feed in sediment mixture and water, considering that, in the short-term and short distance, rivers can be compared to feed systems with a given initial slope.

[8] Local bed slopes and mean bed slope (difference between the bed height at the flume entrance and the bed height at the flume outlet divided by the total flume length) were measured every $10-20 \mathrm{~min}$ along the flume sidewall using eight staff gauges placed $1 \mathrm{~m}$ apart, starting at the channel outlet. Since flows were two-dimensional in all our runs, it was easy to define a reference bed level corresponding to nonmoving grains (fixed bed) and valid for the flume cross section. However, in some runs (essentially for the $15-\mathrm{cm}$-wide flume) we averaged two readings obtained from both sides of the flume. We considered only the long-term bed changes because there were no large bed forms (such as dunes) capable of changing the bed topography in our experiments. When antidune waves were present, we averaged several measurements so as to consider the mean bed level at the flume control section. We estimate that the error made on the fixed bed level reading was no more than $5 \mathrm{~mm}$. But in many experiments including the $2.3-\mathrm{mm}$ sediment, bed load transport developed above a bed consisting of the $2.3-\mathrm{mm}$ material with very few asperities, resulting in greater precision. In addition, the measurements were repeated many times for all control sections, also reducing the error. Consequently, the error in slope calculation (when considering the entire flume length) was estimated to be within $3 \%$ for the 8 -m-long flume experiments (used in the following analysis). This error could attain $5 \%$ in the 2 -m-long flume used to extend long flume observations to a wider range of flow conditions and sediment mixtures. The energy slope was not measured. 
Table 1. Experimental Conditions and Main Results ${ }^{\mathrm{a}}$

\begin{tabular}{ccccccccccccccccc}
\hline \multirow{2}{*}{$\begin{array}{c}\text { Run } \\
\text { Number }\end{array}$} & \multicolumn{3}{c}{ Mixture Composition } & & & & & & & & & & \multicolumn{4}{c}{$Q$ Qs Maximum $(\mathrm{g} / \mathrm{s})$} \\
\hline 1 & 50 & 0 & 50 & 0.15 & 8 & 5.00 & 14.40 & 1.80 & $42-45$ & 1.17 & $0.8-1.5$ & 22.0 & \pm 0.20 & 16.2 & 0.0 & 15.8 \\
2 & 50 & 50 & 0 & 0.10 & 2 & 0.80 & 5.41 & 3.30 & $16-17$ & 1.21 & $0.9-1.4$ & 2.3 & \pm 0.35 & 5.9 & 4.4 & 0.0 \\
3 & 50 & 50 & 0 & 0.10 & 2 & 0.60 & 8.17 & 4.55 & $13-13$ & 1.23 & $1.0-1.6$ & 1.8 & \pm 0.45 & 13.1 & 7.3 & 0.0 \\
4 & 50 & 50 & 0 & 0.10 & 2 & 0.70 & 13.10 & 4.65 & $15-15$ & 1.25 & $1.1-1.7$ & 1.7 & \pm 0.35 & 14.7 & 10.5 & 0.0 \\
5 & 50 & 50 & 0 & 0.10 & 8 & 0.80 & 18.05 & 4.85 & $15-16$ & 1.30 & $1.3-1.9$ & 22.0 & \pm 0.15 & 17.7 & 14.6 & 0.0 \\
6 & 50 & 50 & 0 & 0.05 & 8 & 0.17 & 10.38 & 8.60 & $09-10$ & 1.19 & $1.2-1.8$ & 64.0 & \pm 0.40 & 10.0 & 7.0 & 0.0 \\
7 & 50 & 50 & 0 & 0.05 & 8 & 0.20 & 13.53 & 8.65 & $10-11$ & 1.23 & $1.4-2.0$ & 46.0 & \pm 0.35 & 11.7 & 10.3 & 0.0 \\
8 & 50 & 50 & 0 & 0.05 & 8 & 0.24 & 19.90 & 8.40 & $11-12$ & 1.27 & $1.5-2.2$ & 33.0 & \pm 0.30 & 12.4 & 14.0 & 0.0 \\
9 & 50 & 50 & 0 & 0.05 & 8 & 0.30 & 29.93 & 8.85 & $11-14$ & 1.34 & $1.9-2.5$ & 5.0 & \pm 0.15 & - & - & - \\
10 & 50 & 50 & 0 & 0.05 & 8 & 0.40 & 40.85 & 9.06 & $13-17$ & 1.44 & $2.3-2.8$ & 2.5 & \pm 0.18 & - & - & - \\
11 & 30 & 70 & 0 & 0.10 & 2 & 0.80 & 12.83 & 4.60 & $16-16$ & 1.27 & $1.2-1.6$ & 1.0 & \pm 0.37 & 10.6 & 13.5 & 0.0 \\
12 & 30 & 70 & 0 & 0.10 & 2 & 0.90 & 13.91 & 4.60 & $16-18$ & 1.29 & $1.3-1.8$ & 0.5 & \pm 0.35 & 15.6 & 14.3 & 0.0 \\
13 & 30 & 70 & 0 & 0.10 & 2 & 1.10 & 24.70 & 4.70 & $18-20$ & 1.34 & $1.5-2.0$ & 0.7 & \pm 0.30 & 15.6 & 19.8 & 0.0 \\
14 & 30 & 70 & 0 & 0.10 & 2 & 1.30 & 33.91 & 4.90 & $19-23$ & 1.39 & $1.8-2.2$ & 0.7 & \pm 0.14 & 14.6 & 25.6 & 0.0 \\
15 & 0 & 50 & 50 & 0.10 & 2 & 1.50 & 39.52 & 5.80 & $25-25$ & 1.21 & $1.2-1.7$ & 0.9 & \pm 0.30 & 0.0 & 45 & 27.4 \\
16 & 0 & 50 & 50 & 0.10 & 2 & 1.80 & 61.00 & 5.95 & $27-29$ & 1.26 & $1.4-2.0$ & 0.5 & \pm 0.15 & 0.0 & 29.8 & 34.8 \\
17 & 40 & 20 & 40 & 0.10 & 2 & 1.20 & 11.97 & 4.10 & $20-22$ & 1.27 & $0.8-1.6$ & 0.8 & \pm 0.80 & 16.8 & 6.8 & 10.6 \\
18 & 33 & 33 & 33 & 0.10 & 2 & 0.80 & 19.00 & 6.00 & $15-17$ & 1.31 & $0.8-1.7$ & 0.5 & \pm 0.80 & 18.2 & 24.5 & 18.1 \\
19 & 50 & 50 & 0 & 0.15 & 4 & 4.00 & 3.80 & 0.95 & $42-43$ & 0.96 & $0.8-1.2$ & 3.5 & \pm 0.05 & - & - & - \\
20 & 50 & 50 & 0 & 0.15 & 4 & 6.00 & 7.00 & 0.86 & $57-58$ & 0.92 & $1.0-1.5$ & 4.0 & \pm 0.04 & - & - & - \\
\hline
\end{tabular}

${ }^{\mathrm{a}} W$, flume width; $L$, flume length; $Q$, inlet fluid discharge; $Q s$, inlet solid discharge; $S$, mean bed slope; $H$, flow depth calculated for maximum slope with coarse bed and minimum slope with fine bed; $F r$, Froude number; $\theta / \theta_{c}$, extreme values for the ratio of the Shields number $\theta$ to its critical value considering the slope and bed surface grain diameter variations; $T$, duration of the run; $d S$, amplitude of the fluctuation around the mean bed slope value, $Q s$ Maximum, point bed load values obtained during bed load sheet at the flume outlet for each mixture size.

However, in most runs the flow was supercritical and the bed slope fluctuation was slow enough to maintain a free water surface that was always in phase with the bed. The bed slope therefore approximated the energy slope well.

[9] Sediment feeding rates were measured from the feeding system calibration, and outlet transport rates were obtained from dried and weighed samples collected in a basket at the flume outlet during bed load sheet passage. Sampling lasted between 1 and $3 \mathrm{~min}$ and three to four samples were collected for a given run. For run 7 , we measured continuous outlet solid discharge with a customized video system [Frey et al., 2003a]. At the outlet of the flume, the mixture of sand, gravel and water was forced to flow on a tilting transparent ramp placed above an illuminated waterproof box. A video camera was placed above the plate and operated in backlighted mode. Software with specific libraries was developed to grab and save series of several images. These images were then processed with an algorithm (WIMA software [Ducottet, 1994]) using specific image analysis methods, the main steps being (1) segmentation based on gradient operators and hysteresis thresholding, (2) object separation based on an erosion algorithm, and (3) object measurement, i.e., area and diameters after determining principal axes. Finally, from a series of 2-D images as input, the algorithm calculated the three principal dimensions of each particle using an ellipsoid-shaped model. This system was used to measure total and fractional solid discharge every $0.05 \mathrm{~s}$ over an integration period of $3 \mathrm{~s}$.

[10] The bed surface and subsurface grain size distribution were estimated in different ways. Since we used essentially bimodal mixtures, on many occasions of interest (transport above a paved bed and transport over a smooth bed after pavement destruction), it was possible to estimate the bed surface grain size visually. Direct sampling was also carried out by incorporating a customized short plastic pipe into the bed [Recking, 2006]. The bed surface sediment was first removed over a thickness of approximately one grain diameter when the subsurface was sampled.

\subsection{Flow Conditions}

[11] The flow conditions are presented in Table 1 (Run Number- $T$ columns). All experiments were conducted with constant ingoing flow and sediment discharge. For each run, measurements were made only after attaining a dynamic equilibrium condition, i.e., near equality of the feed and trap rates for each fraction of the sediment mixture, and a near constant time-averaged bed slope. The procedure to match flow and sediment transport so as to obtain dynamic equilibrium for a given flow and flume slope consisted of calculating an equilibrium transport rate using equations (1) and (4) defined below, considering the mean diameter of the sediment mixture. Setting this calculated feed value at the flume entrance, the run was maintained until the slope attained a constant average slope. In these constrained flume experiments, and considering mass conservation, the constant average slope was necessarily associated with an equilibrium average transport rate for a feeding rate that was maintained constant. This was confirmed with image analyses in run 7.

[12] Long experiments were conducted to obtain dynamic equilibrium (eight runs lasted between 4 and $64 \mathrm{~h}$ ). Shorter experiments (12 runs lasting less than $4 \mathrm{~h}$ ) were also conducted with a reduced flume length $(2-4 \mathrm{~m})$ and by varying either the sediment mixture or the flow discharge. The principal objectives for these shorter experiments were to extend the long experimental observations to a wider range of flow conditions and sediment mixtures, and only long-duration experiments conducted in long flumes were used for a detailed analysis. Long runs (64 h for run 6) had to be stopped and started again many times. The procedure always involved acting as slowly as possible (flow and 

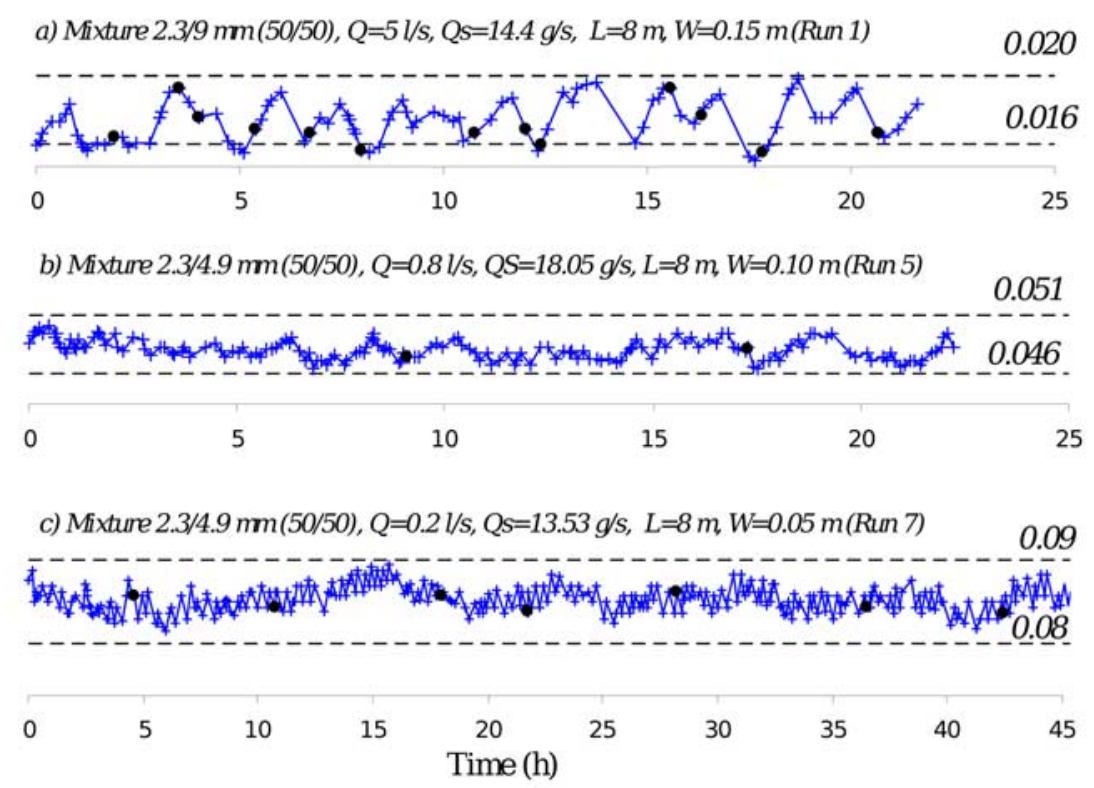

Figure 1. Mean bed slope fluctuations measured for (a) run 1 (slope 0.018, mixture 2.3 and $9 \mathrm{~mm}$ ), (b) run 5 (slope 0.05, mixture 2.3 and $4.9 \mathrm{~mm}$ ), and (c) run 7 (slope 0.086, mixture 2.3 and $4.9 \mathrm{~mm}$ ); crosses indicate measurements and dots indicate run stops.

sediment feed rate shutting off/starting up) in order not to disturb the bed material size. In the following, every run designated by its slope corresponds to the dynamical equilibrium average slope resulting from the imposed feeding rates and sediment mixture. The feeding rates were changed for every run in order to test equilibrium slopes between 1 and $9 \%$. Maximum and minimum values of the Shields number, $\theta=\tau /\left[g\left(\rho_{s}-\rho\right) D\right]$ where $\tau=\rho g R S$ is the bed shear stress, $R$ is the hydraulic radius, $\rho_{s}$ is the sediment density and $\rho$ is the water density, in Table 1 were calculated considering variations of the bed surface grain diameter observed during the run and the maximum and minimum slopes averaged over the entire flume length $(S \pm \mathrm{d} S)$.

\subsection{Friction and Bed Load Transport Equations}

[13] The friction (equation (1)) and bed load transport (equation (4)) equations based on previous uniform sediment experiments [Recking et al., 2008b] are reviewed here. These equations were used to analyze the nonuniform results

$$
\frac{U}{\sqrt{g R S}}=6.25+5.75 \log \left(\frac{R}{\alpha_{R L} \alpha_{B R} D}\right),
$$

where $U$ is the vertically averaged flow velocity,

$$
\begin{gathered}
\alpha_{R L}=4\left(\frac{R}{D}\right)^{-0.43} \text { with } 1 \leq \alpha_{R L} \leq 3.5 \\
\alpha_{B R}=7 S^{0.85} \frac{R}{D} \text { with } 1<\alpha_{B R} \leq 2.6
\end{gathered}
$$

where $\alpha_{R L}$ is a roughness layer coefficient taking into account deviation from the logarithmic profile at small relative depth flows (with an increasing influence of the roughness layer) and $\alpha_{B R}$ is a bed load roughness coefficient taking into account additional flow resistance due to bed load. The bed load equation (valid for low flow conditions with $\left.\theta<2.5 \theta_{c}\right)$ is

$$
\phi=15.6\left(\theta-\theta_{c}\right)^{2}
$$

With

$$
\theta_{c}=0.15 S^{0.275}
$$

where $\phi=q_{s v} /\left[g(s-1) D^{3}\right]^{0.5}$ is the Einstein dimensionless parameter [Einstein, 1950] and $q_{s v}\left[\mathrm{~m}^{3} / \mathrm{s} / \mathrm{m}\right]$ is the volumetric unit solid discharge. Equation (5) yields greater values of dimensionless critical shear stress for increasing values of slope, as explained by the effects of changing flow hydraulics with increasing slope and decreasing relative depth [Lamb et al., 2008; Recking, 2009].

\section{Results of the Experiments \\ 3.1. Bed Load and Slope Fluctuations}

[14] The results are presented in Table $1(d S-Q s$ Maximum columns). For all runs, large fluctuations of both the slope and the outlet solid discharge $\left(Q_{s}\right)$ were observed although the feedings were maintained constant. Figure 1 presents the mean bed slope fluctuation measured in run 1 , run 5 and run 7 . These long runs indicate that the mean bed slope fluctuations ( $d S$ column) were associated with several periods. In all runs, the bed slope fluctuation was particularly well observed in the upstream section of the flume. Figure 2 presents the local bed slope measured for run 7 at the flume entrance over a distance of $2 \mathrm{~m}$ and indicates high fluctuations around a mean value over short periods of time. This was responsible for the short fluctuations of the mean bed slope (calculated over the entire flume length) shown in 


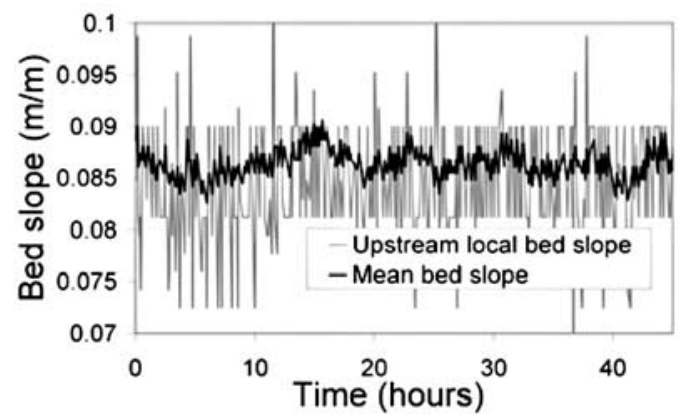

Figure 2. Local slope fluctuation measured at the flume entrance (over a distance of $2 \mathrm{~m}$ ) and mean bed slope fluctuation measured over the entire flume length in run 7.

Figure 1c. This local upstream slope fluctuation was easier to observe on steep slopes but was present in all experiments. It was always associated with very precise and repetitive bed state changes (bed fining and paving), as was observed by Iseya and Ikeda [1987] in the upstream section of their flume (their Figure 5). Kuhnle and Southard [1990] also described periodical aggradation alternating with briefer periods of degradation in the upstream section of the channel in an aggrading flume experiment.

[15] Figure 3 presents slope and bed load fluctuations measured continuously at the flume outlet in run 7 using image analysis. The inlet solid discharge versus time was obtained from the conveyor belt velocity recording. The average outlet solid discharge reached the imposed inlet value and the mean bed slope equaled 0.086 . For this run, the bed load fluctuated between roughly twice the mean input value and nearly zero. The outlet solid discharge was measured continuously only for run 7; in other runs, the maximum outlet solid discharges for each fraction of the sediment mixture ( $Q s$ Maximum columns) are point bed load values obtained by sampling several bed load sheets at the flume outlet (the maximum discharge associated with an individual bed load sheet was approximately constant for a given run).

[16] Figures 1 and 3 show that both the slope and the outlet solid discharge fluctuate around a mean constant value, indicating that a dynamic equilibrium was attained, although both variables fluctuated to a great extent. The initial bed surface condition (flow over initially eroded/ aggraded beds and well-sorted coarse/fine sediments) was observed to change the response delay but did not fundamentally change the fluctuating process in these feed flume experiments. These fluctuations were not observed in similar experiments conducted with uniform sediment [Recking et al., 2008a], which confirms that, for the experimental design considered, fluctuations are a consequence of grain sorting in mixed sediments.

\subsection{Grain Sorting and Bed Load Sheet Production}

[17] In all runs, aggradation was always associated with reduced gravel mobility for all diameters, and a very efficient vertical and longitudinal grain sorting, sometimes occurring with a wavy bed surface. This resulted in a progressive bed surface coarsening and subsurface fining. Figure 4 presents the results of bed sample measurements in run 7 and indicates that the subsurface fining was very efficient over a finite length (approximately $2 \mathrm{~m}$ ) immediately downstream of the feeding section. Aggradation always stopped when the local slope attained a maximum value. In all runs, it was immediately followed by an abrupt gravel mobility increase producing local bed erosion and transport of finer gravels that had previously been stored inside the bed. When a pavement was present, it was always destroyed. Erosion was maintained until the constant solid discharge at the flume entrance imposed a new aggradation. In all of our experiments, these local "sediment purges" coincided with bed load sheet departure.

\subsection{Bed Load Sheet Migration}

[18] Figure 5 illustrates alternating states observed for each run at a given cross section, which are very similar to those described by Iseya and Ikeda [1987]: high bed load transport over smooth bed (bed load sheet, Figure 5a), transitional (with a wavy bed surface, Figure $5 \mathrm{~b}$ ) and low bed load transport over congested states (Figure 5c). Figure 6 shows images of the bed topography taken at the same location just before (Figure 6a) and during (Figure 6b) the passage of a bed load sheet in run 7 (mixture, $2.3 \mathrm{~mm}$ and $4.9 \mathrm{~mm} ; 9 \%$ slope). At the bed load sheet's leading edge, Figure 6a shows coarse sediment saltating above coarse sediments at rest forming the bed surface. During

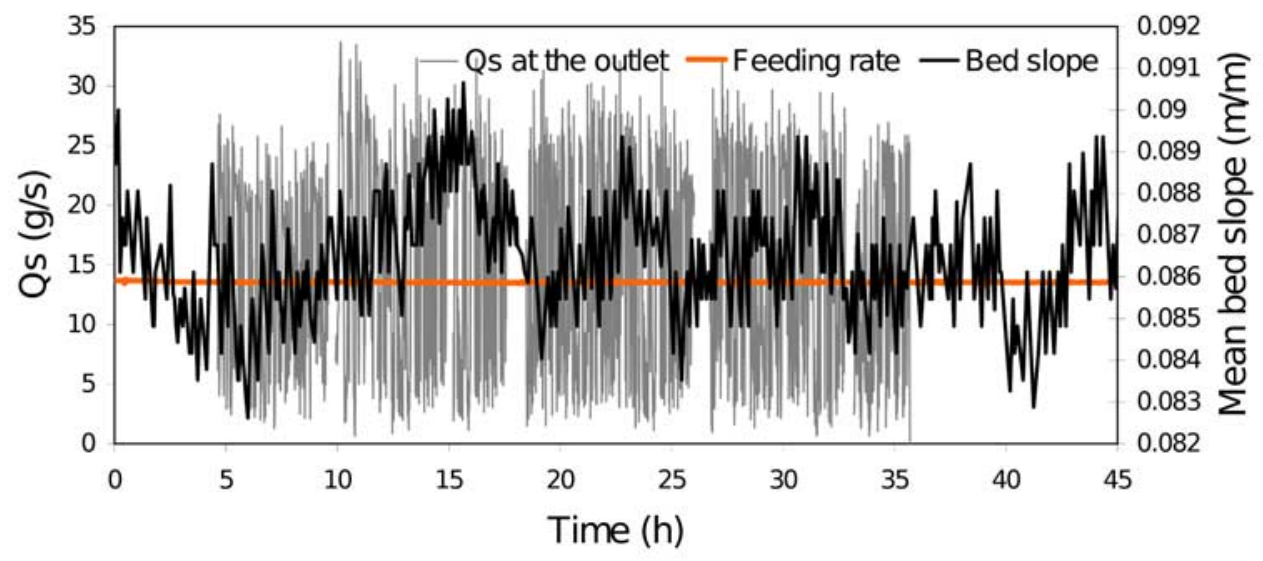

Figure 3. Continuous outlet solid discharge and mean bed slope versus time for run 7 . 


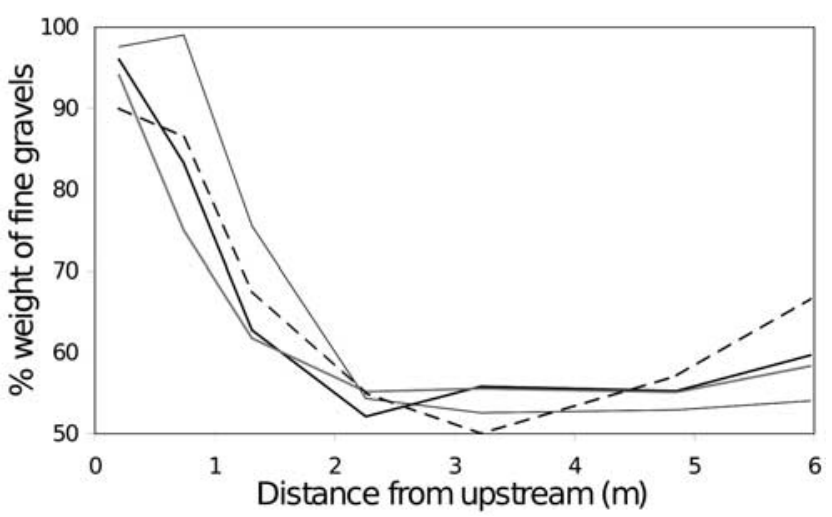

Figure 4. Four bed samplings in run 7 indicating subsurface fining over a finite distance in the flume's upstream section.

the passage of the bed load sheet (approximately $30 \mathrm{~s}$ later), the bed level was located at approximately one (coarse) grain diameter above the initial level and the bed grain size distribution looked finer. The gentler the slope the smaller the bed load sheet height. On gentle slope experiments $(1 \%)$, bed load sheets had such low heights that they were distinguishable only by their relatively fine and coarse bed surface areas and sediment mobility (as described by Bennett and Bridge [1995] in their 0.2\% slope experiment). Moreover, the gentler the equilibrium slope, the lower the grains' displacement velocity; the bed load sheet migration velocity was approximately $0.6 \mathrm{~cm} / \mathrm{s}$ on a $2 \%$ slope and $1.4 \mathrm{~cm} / \mathrm{s}$ on a 9\% slope (Kuhnle and Southard [1988] measured $0.5-1 \mathrm{~cm} / \mathrm{s}$ in a $2 \%$ slope experiment and Iseya and Ikeda [1987] measured approximately $0.8 \mathrm{~cm} / \mathrm{s}$ in a $3 \%$ slope experiment). As a consequence, the time needed to observe bed load sheet production and migration was longer in gentle slope experiments. In comparison, the estimated time period for bed load sheet production was more than $1 \mathrm{~h}$ in the $1 \%$ equilibrium slope experiments and roughly $15 \mathrm{~min}$ in the $9 \%$ equilibrium slope experiments.

[19] Bed load sheets seemed to be ephemeral in nature, progressively disappearing by interacting (by vertical and longitudinal grain sorting) during their migration with the bed pavement in place. After the passage of a bed load sheet, the pavement was locally destabilized and even destroyed, producing a smoother bed usually affected by antidune waves (Figure 5b). This transitional state quickly evolved toward a new pavement (Figure 5c) because of efficient grain sorting, but some dislodged coarse gravels were observed to be transported by the flow and accelerated when passing above the migrating bed load sheets (as was observed by Iseya and Ikeda [1987]). Because of their high displacement velocity, these gravels contributed to destabilizing the subsequent congested bed when impacting gravels at rest (which is consistent with the impact effect observed by Kuhnle and Southard [1988]). As a consequence of successive bed load sheet passages, alternating smooth, intermediate and congested states were observed temporally at a given cross section. The space distribution was slightly different, with alternating smooth, congested and transition-

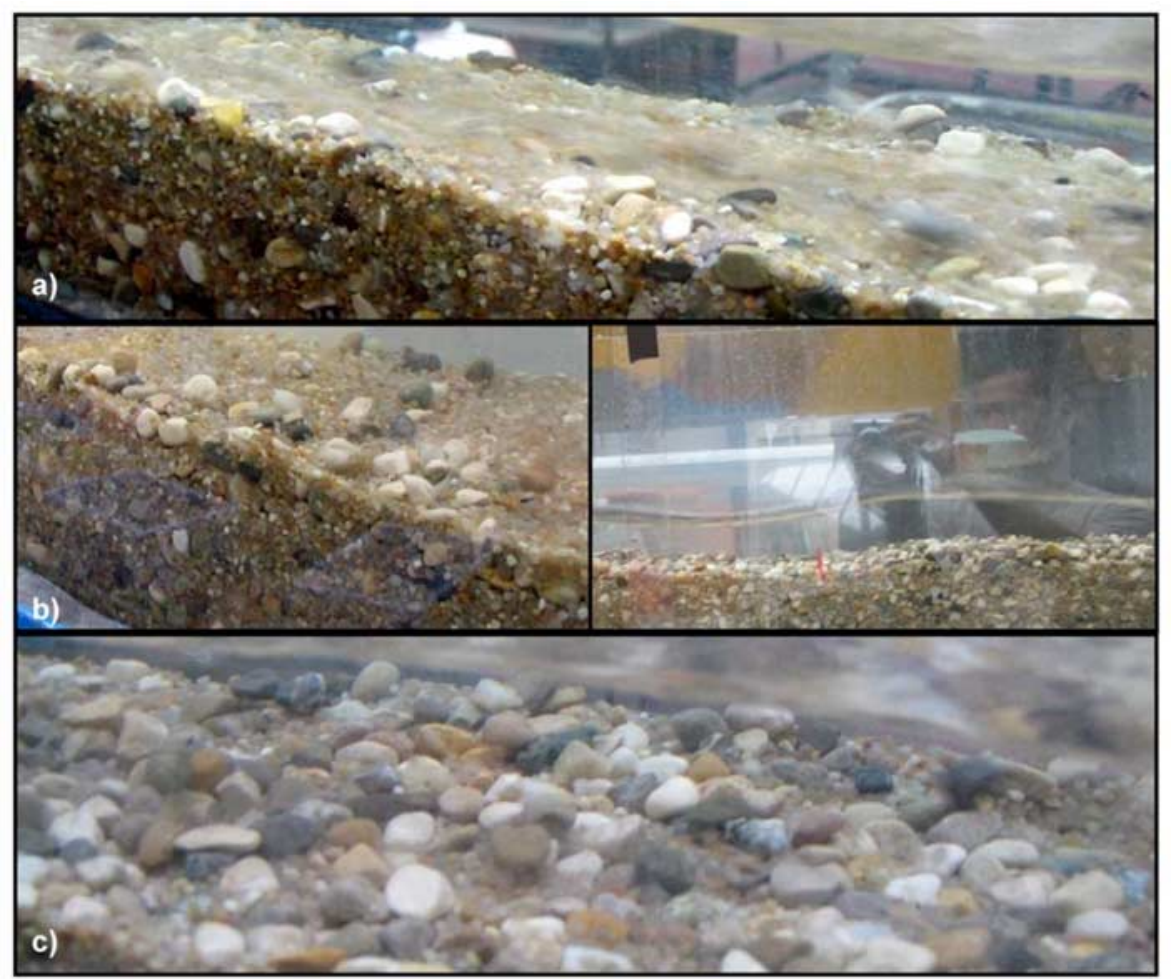

Figure 5. Alternating bed states observed at a given cross section (in the following order) in run 1 (slope 2\%, mixture 2.3 and $9 \mathrm{~mm}$ ): (a) smooth (high transport rate of all gravel fractions), (b) transitional (with antidune waves), and (c) congested (low transport rate over paved bed). 


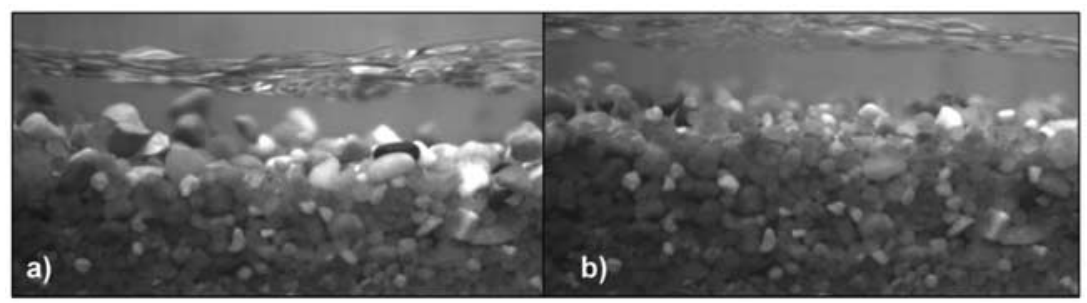

Figure 6. Two images of the bed state taken (a) just before and (b) during the passage of a bed load sheet in run 7 (slope $9 \%$, mixture 2.3 and $4.9 \mathrm{~mm}$ ). The flow is from left to right and the time between images is $30 \mathrm{~s}$.

al states observed in the streamwise direction (as was described by Iseya and Ikeda [1987] in their Figure 5).

[20] Bed load sheets were responsible for the short fluctuation periods. Longer periods corresponded to complex long-term bed surface changes while interacting with successive downstream migrating bed load sheets. In most cases in long experiments, the pavement was periodically spread over part or all of the flume length, followed by substantial bed erosion. Bed load sheets produced on these occasions were very long and associated with total bed pavement destruction. As a consequence, bed load sheets were not observed uniformly in space and time. Most of the time, they were very short, ephemeral and essentially produced in the upstream part of the flume before migrating downstream. However, local departures were also observed elsewhere in the flume, less frequently and usually in association with greater bed erosion.

\section{Analysis}

\subsection{Maximum Slope and Solid Discharge}

[21] All short and long erosions produced very contrasted and fluctuating bed topographies (slope variation). The mean and local bed slope always fluctuated between two extreme values depending on the sediment mixture and inlet discharges (Figure 1). For each run characterized by the flow discharge, the sediment discharge and the mean diameter ( $D=\Sigma m_{i} D_{i}$ where $m_{i}$ is the fraction by weight of sediment

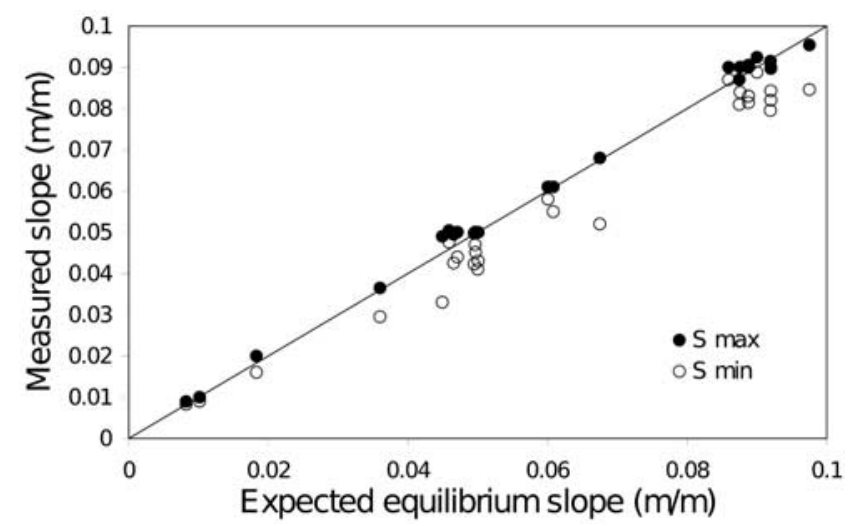

Figure 7. Comparison between maximum and minimum slope values obtained with (injected) poorly sorted sediments of mean diameter $D$ with the equilibrium slope that would have been obtained with uniform sediment of the same diameter $D$. diameter $D_{i}$ within the mixture) of the injected sediment mixture, measured slopes (a maximum and a minimum) are compared in Figure 7 with the slope that would have been obtained at equilibrium with a uniform sediment of the same diameter $D$ (using equations (1) and (4)). One can deduce from Figure 7 that, in the fluctuating process, the maximum slope for aggradation is equivalent to the slope that would have been obtained at equilibrium with a uniform sediment for the given mean diameter $D$, feeding rate and flow conditions.

[22] Figure 8 presents the maximum to mean slope and bed load transport rate ratios versus $\theta / \theta_{c}: \theta$ was calculated with equation (1) considering the pavement grain size and $\theta_{c}$ was defined by equation (5) (but the trend presented in Figure 8 would have remained unchanged with a constant $\theta_{c}$ value). This indicates that fluctuation amplitudes were decreased with increasing flow conditions and nearly disappeared when $\theta / \theta_{c}>2$. This value was also observed to be a key value for coarse sediment mobility in other studies [Church and Hassan, 1998; Wilcock and McArdell, 1993]; Iseya and Ikeda [1987] and Kuhnle [1989] also observed that bed load fluctuations became smaller when the mean bed load increased.

\subsection{Fractional Transport Rate}

[23] Image analysis was used to measure fractional transport rates in run 7 (2.3- and 4.9-mm mixture, $Q=$ $0.2 \mathrm{l} / \mathrm{s} ; Q_{\mathrm{s}}=13 \mathrm{~g} / \mathrm{s}$, mean bed slope $8.6 \%$ ). The experiment lasted $45 \mathrm{~h}$ and instantaneous outlet solid discharge was measured at the flume outlet for $30 \mathrm{~h}$. Figure 9 is an

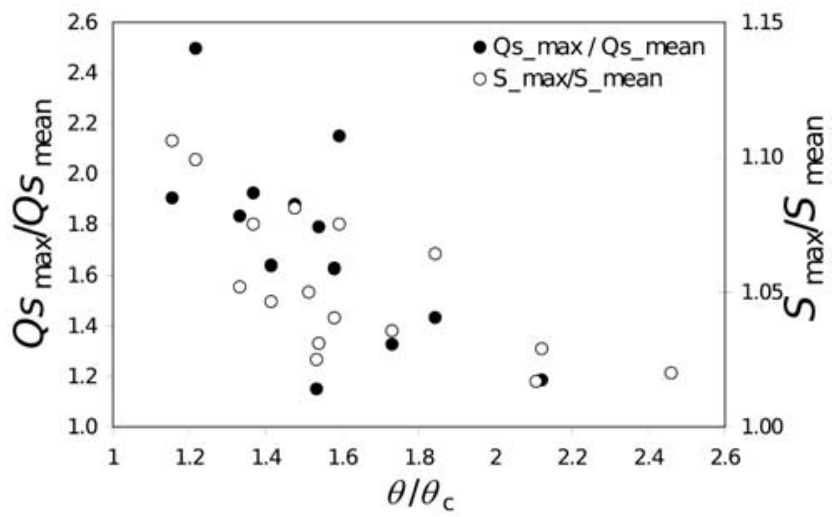

Figure 8. Decreasing bed load and slope fluctuation with increasing flow conditions $\left(\theta / \theta_{c}\right.$ calculated for the pavement grain size). 


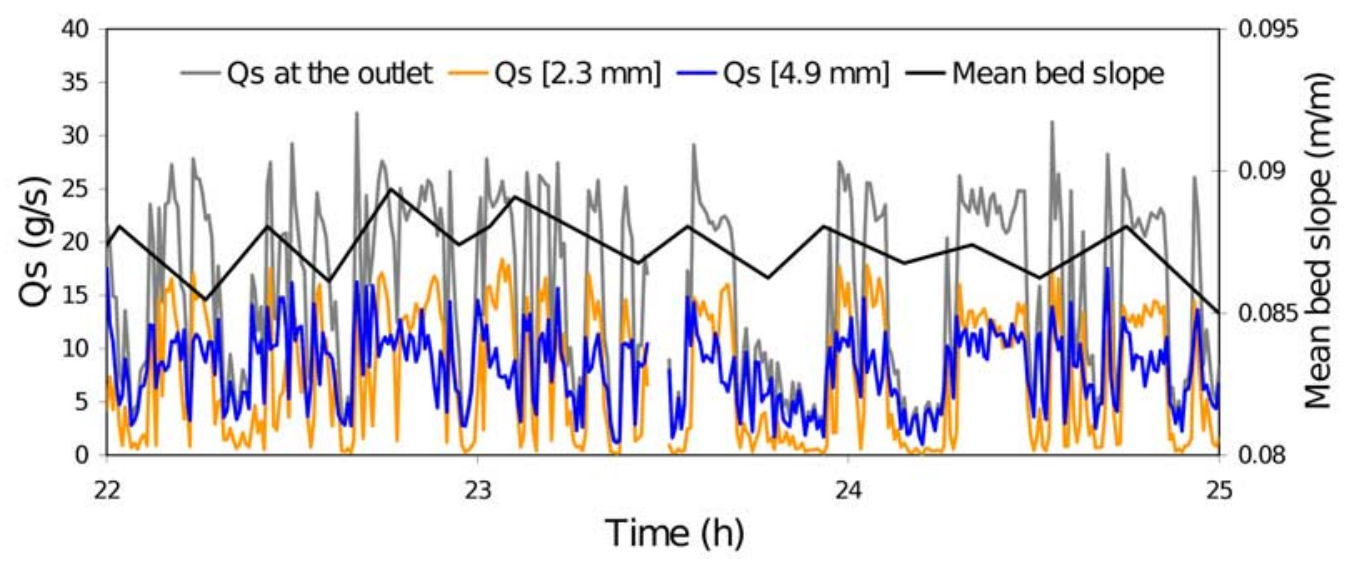

Figure 9. Increased resolution view of the 22- to 25 -h period from Figure 2 showing the fractional and total transport rate for run 7 .

increased resolution view of Figure 3 for the period lasting $22-25 \mathrm{~h}$ and presents the fractional transport rates measured for both gravel sizes. It illustrates the correlation between bed load and bed slope, with aggrading beds systematically associated with low outlet sediment rates, whereas most peaks are associated with degrading beds. The finer gravel $(2.3 \mathrm{~mm})$ solid discharge closely matched the total solid discharge (at lower values), as was observed by Kuhnle and Southard [1988]. The coarse gravel (4.9 mm) peaks at the beginning of the pulse. This is consistent with a gravel peak controlled by impact effects at the leading edge of the migrating bed load sheets. But Figure 9 also indicates that after the peak, the coarse gravel transportation is maintained at a high level during the pulse, which confirms the efficient transport of coarse gravels over the smoothed bed generated by the bed load sheet (as suggested by Iseya and Ikeda [1987]).

[24] The greater mobility of coarse gravels, when transported within bed load sheet, was tested by comparing the fractional transport rate of each gravel fraction (2.3 and $4.9 \mathrm{~mm}$ ) of run 7 to the expected transport capacity of these gravels when used alone in the same flow conditions. The transport capacity of uniform sediments at equilibrium was calculated using equations (1) and (4). This equation derivation was detailed by Recking et al. [2008b], but to make sure that they adequately reproduce uniform sediment transport in the conditions used for run 7, a few additional experiments were conducted in equilibrium flow conditions with 2.3 and $4.9 \mathrm{~mm}$ uniform sediments in a 5-cm-wide flume, on a $9 \%$ slope (Figure 10). Whereas calculations give $5 \mathrm{~g} / \mathrm{s}$ for the $4.9-\mathrm{mm}$ sediment and $18.9 \mathrm{~g} / \mathrm{s}$ for the $2.3-\mathrm{mm}$ sediment (the algorithm used for calculations takes into account a sidewall effect and is presented by Recking [2006]), measurements gave $5.6 \mathrm{~g} / \mathrm{s}$ and $16.3 \mathrm{~g} / \mathrm{s}$, respectively, a very satisfactory result. Figure 11 presents the results of calculations when considering the mean bed slope fluctuation with time $(0.084<S<0.088$ for the period considered). It should be noted that every time the finer gravel $(2.3 \mathrm{~mm})$ solid discharge was reduced to zero, the coarse gravel $(4.9 \mathrm{~mm})$ solid discharge matched the transport capacity of the same diameter used as uniform sediment. However, when the finer gravel solid discharge was nonzero, the coarse gravel solid discharge was usually much higher, with peaks attaining four times this value. This observation appears more clearly in Figure 12 where the coarse sediment $(4.9 \mathrm{~mm})$ transport rate is plotted against the fine sediment $(2.3 \mathrm{~mm})$ transport rate: the coarse gravel transport rate in the presence of fine gravels was on average twice the transport capacity of this coarse gravel used as a uniform sediment in the same flow condition. This result confirms that coarse gravels have a much higher mobility when transported with finer gravels. With the impact effect observed at the bed load sheet's leading edge, it explains that the coarse gravel peak solid discharge can be very high at the beginning of the sediment pulse associated with bed load sheet migration. However, the fine gravel solid discharge values are usually much lower than the values expected with the transport of uniform diameter sediment. These expected values are attained during bed load sheet passages. This means that the mobility of fine gravels is strongly affected by grain sorting except when they are transported in the bed load sheet mixture.

\subsection{Correlation Between Bed Load Sheet Production and Local Bed Topography Changes}

[25] Relations between the upstream slope fluctuation and bed load sheets measured at the flume outlet were investigated through signal analyses. Figure 13 presents a spectral analysis obtained with a Fourier transform of temporal signals $Q s(\mathrm{t})$ and $S(\mathrm{t})$ shown in Figure 9, considered with a time step equal to $60 \mathrm{~s}$, and scaled by their respective average values: $[Q s(t)-\overline{Q s}] / \overline{Q s}$ (where $\overline{Q s}$ is the average

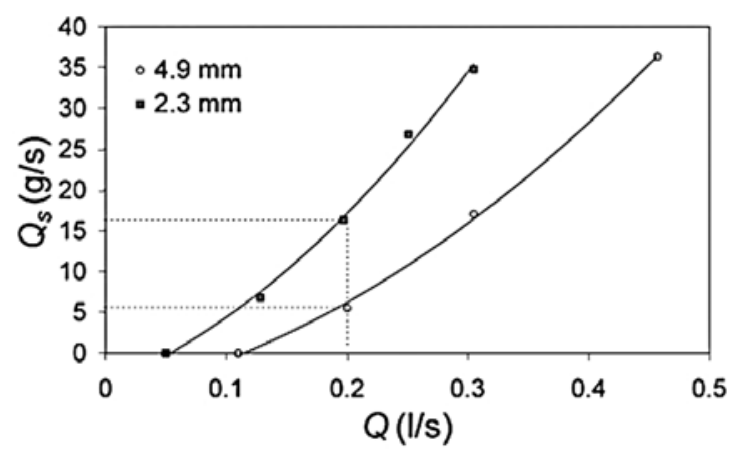

Figure 10. Transport rate measured at capacity on a $9 \%$ slope for the 2.3- and 4.9-mm uniform sediments. 


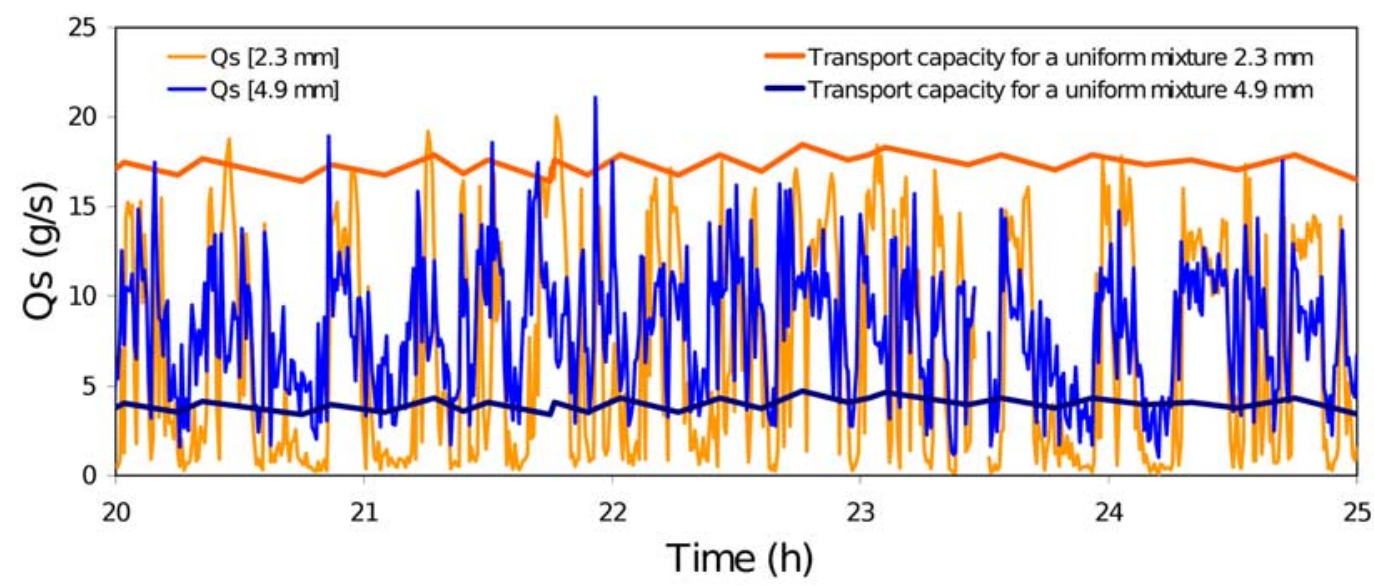

Figure 11. Plot of coarse sediment $(4.9 \mathrm{~mm})$ transport rate against fine sediment $(2.3 \mathrm{~mm})$ transport rate of run 7 .

solid discharge) and $[S(t)-\bar{S}] / \bar{S}$ (where $\bar{S}$ is the average mean bed slope). The power of the slope signal decreases rapidly when frequencies approach 0.1 because the time step for slope measurements was generally higher than or equal to $10 \mathrm{~min}$. The outlet solid discharge was measured continuously and consequently the power shown in Figure 13 continues to decrease progressively for frequencies higher than 0.1. However, these high frequencies correspond to very short time fluctuations occurring within bed load sheets (as shown in Figure 9) and at the grain scale. They could hardly be interpreted and were not considered in the analysis. We identified three families of peaks in Figure 13, corresponding to short fluctuation periods $(10-45 \mathrm{~min})$, intermediate fluctuation periods $(1.2-2.6 \mathrm{~h})$ and long fluctuation periods $(4-7.5 \mathrm{~h})$. These short, intermediate and long periods are highly representative of the slope signal when considered visually in Figure 3.

[26] Both signals $Q_{s}(\mathrm{t})$ and $S(\mathrm{t})$ have approximately the same frequency signature, which confirms that bed load fluctuations were correlated with the bed slope fluctuations. This is particularly true for high frequencies, which indicates that bed load sheets measured at the flume outlet were well correlated with the slope fluctuation we measured at the flume entrance. The periodogram does not clearly

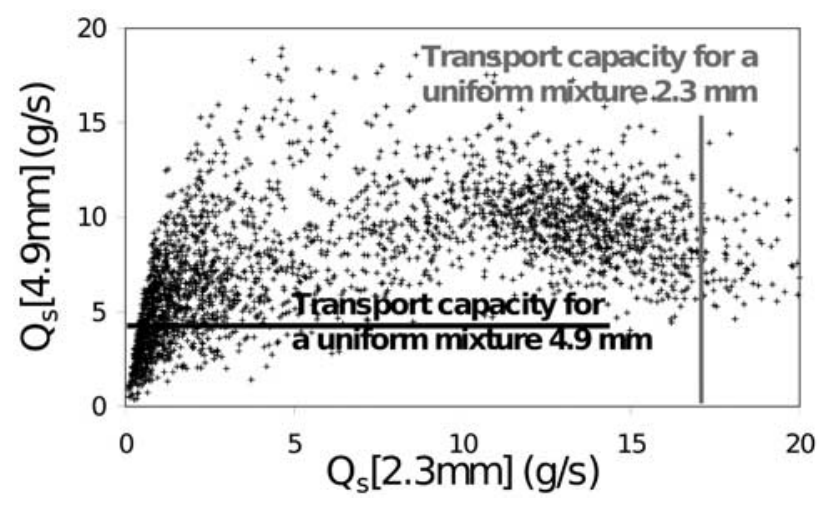

Figure 12. Comparison between fractional transport rates of run 7 with expected transport capacities of uniform sediments for the same flow conditions ( $Q, Q s$, and slope). identify a dominant peak for high frequencies. Instead it shows a continuous spectrum variation which indicates that the duration of the short bed load and bed slope fluctuations are not constant but continuously change with time. Figure 14 presents the duration for each successive aggradation and erosion cycle obtained by a decomposition of the slope signal shown in Figure 2; this duration varied greatly between $8 \mathrm{~min}$ and $44 \mathrm{~min}$ with a mean cycle duration of $20 \mathrm{~min}(8 \mathrm{~min}$ for aggradation and $12 \mathrm{~min}$ for erosion). These durations correspond approximately to the high frequencies $0.022,0.044$ and 0.1 (periods $45 \mathrm{~min}, 22 \mathrm{~min}$ and $10 \mathrm{~min}$, respectively) shown in Figure 13. This confirms that the successive erosion events we observed in the flume's entrance were responsible for the bed load sheets we measured at the flume's outlet.

\section{Discussion}

\subsection{Grain Sorting}

[27] Was the longitudinal and vertical grain sorting observed just downstream of the sediment feed influenced by the injection method? In an attempt to answer this question, the experimental setup was tested with different feeding devices (a volumetric sediment feeder was also tested) as well as different feeding configurations, with or without water or solid accompaniment: no changes in the bed behavior were observed, whatever the feeding method

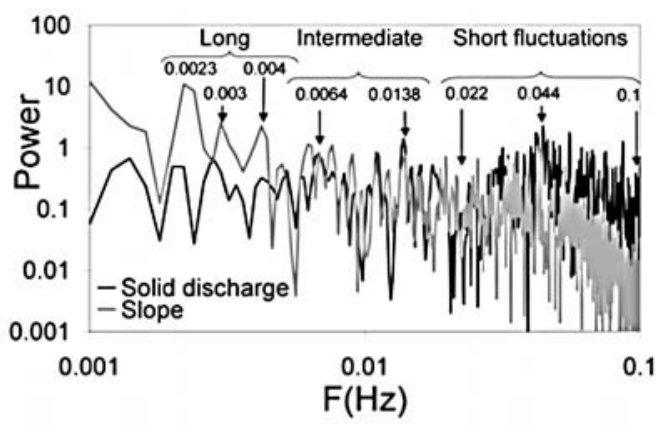

Figure 13. Spectral analysis (Fourier transform) of the mean bed slope and solid discharge in run 7 . 


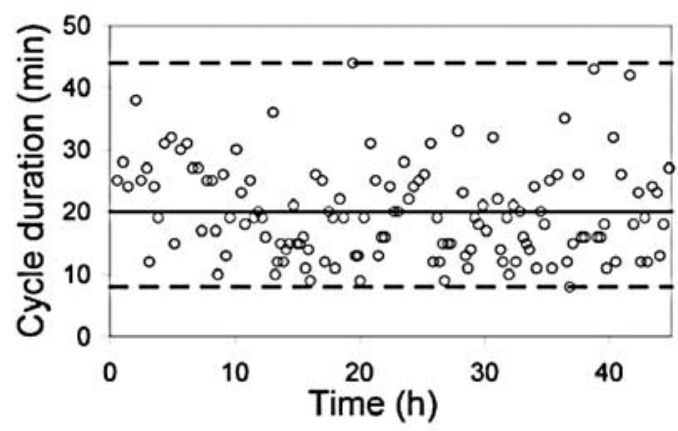

Figure 14. Durations for erosion and aggradation cycles measured at the flume entrance in run 7.

used. Actually, observed longitudinal and vertical grain sorting may instead be inherent to displacement of a sediment mixture, as a very similar phenomenon, including longitudinal and vertical grain sorting over a finite length, has been described without water, in granular flows [Bridgwater, 1969; Drahun and Bridgwater, 1983; Felix and Thomas, 2004; Thomas, 2000].

\subsection{Transport Rate Efficiency}

[28] Higher mobility of coarse gravels when transported within a mixture was demonstrated nearly a century ago by Gilbert [1914]. He conducted specific experiments using mixtures of up to five grades, and also with a natural, poorly sorted gravel material. For a given flow power, the gravel mobility varied with sand content and, in most of his experiments, mobility was maximum with a $50 \%$ sand mixture (as we observed on average in Figure 11). Among other important results, he concluded that the mixture's complexity had no advantage for traction over a mixture of two components only, and he did not observe any influence of the ratio between the coarser and finer grades (tested between 2.9 and 16.2). Like others after him, he attributed this higher mobility to smoother bed surfaces produced when fine sediments filled interstices between coarser sediments, which could affect not only the start-up of gravel motion but also its continuance in motion. Other studies after Gilbert [1914] also demonstrated that fine sediments increase gravel transport efficiency for a given flow condition [Cui et al., 2003; Curran and Wilcock, 2005; Ferguson et al., 1989; Jackson and Beschta, 1984; Raudkivi and Ettema, 1982; Wilcock et al., 2001]. This can also be related to experiments by Jackson and Beschta [1984] and Cui et al. [2003], who observed that injection of fine sediments over a previously armored and immobile bed produced gravel entrainments.

[29] The higher mobility of coarse gravels within a mixture for a given flow discharge (or greater transport rate efficiency for a given available power) can help one to understand the upstream fluctuating process when the flume is fed with constant flow and sediment discharges. Let us consider the energy conservation equation (work rate $=$ input power $\times$ efficiency). For a given available power $P$, the work done $d W / d t$ will depend on an efficiency term $e$

$$
\frac{d W}{d t}=e P
$$

This equation was applied to river flows by Bagnold [1966], who considered the stream to be a continuing steady transport system. He wrote

$$
i_{b} \tan \alpha=e \omega
$$

where $i_{b}=q_{s v} g\left(\rho_{s}-\rho\right)$ is the submerged bed load transport rate $\left(q_{s v}\right.$ is the volumetric solid discharge per unit width), $\tan \alpha$ is the dynamic coefficient of internal friction, $\omega=\tau U$ is the flow power (kinetic energy liberated in a unit of time and subsequently dissipated as heat) and $e$ is bed load transport rate efficiency $(e<1$ as all dissipation does not correspond to the process of solid friction). For a given available power $\omega$, efficiency $e$ decreases with increasing grain diameter $D$, as was demonstrated by Bagnold [1966]. Equation (7) can be written

$$
i_{b} \tan \alpha=e U \rho g H S=e \rho g q S .
$$

For a given sediment mixture and when both the liquid and solid discharges are maintained constant, this expression reduces to

$$
e S=\varphi\left(q, q_{s}\right)=C^{t e}
$$

In other words, when the feeding rates are maintained constant, energy conservation imposes that the product of efficiency by the slope is maintained constant. Consequently, variations in the transport rate efficiency necessarily affect the energy slope.

[30] Considering (1) that the minimum and maximum slope attained during fluctuations (Figure 2) in the upstream section remained constant, (2) results presented in Figure 7 (for all runs the maximum slope was observed to coincide with the slope that would have been obtained at equilibrium for transportation of a uniform sediment of the same diameter as the mean diameter of the sediment mixture), (3) the higher mobility of coarse gravels when transported with finer ones, and (4) the conservation equation (equation (9)), we propose in Figure 15 a scenario for fluctuations observed in the upstream part of the flume and responsible for bed load sheet departure when both the solid and liquid discharges are maintained constant.

\subsection{Field Relevance of This Research}

[31] Such small-scale laboratory experiments cannot be considered a model study of natural systems in the sense that no attempt was made to adjust parameters so that the channel was a dynamical scale model of a much larger channel [Kuhnle and Southard, 1990]. Moreover, it is unsure how the results would have been modified when using a recirculating instead of a feed flume [Parker and Wilcock, 1993]. Bennett and Bridge [1995] obtained bed load sheets in a recirculating flume experiment but because of the very mild slopes considered $(0.2 \%)$ comparison with steep slope results is not straightforward. We used a feed flume to approach the small-scale aspects of grain sorting associated with bed load transport. The advantage of the feed flume is that, by controlling the sediment mixture at the flume entrance, it isolated a complex phenomenon (grain sorting) for observation. On the other hand, a recirculating flume would not have been more representa- 


\begin{tabular}{|c|c|c|c|}
\hline \multicolumn{2}{|c|}{ Observed periodical bed state } & \multirow{2}{*}{ 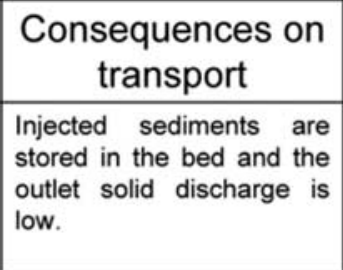 } & \multirow{2}{*}{$\begin{array}{l}\quad \text { Energy } \\
\text { conservation } \\
\text { Low efficiency e } \\
\text { Slope increase until } \\
S=S_{M} \text { verifying } \\
e S_{M}=\varphi\left(q_{s}, q\right)\end{array}$} \\
\hline$\because 0$ & $\begin{array}{l}\text { Aggradation with reduced } \\
\text { gravel mobility. Longitudinal } \\
\text { and vertical grain sorting } \\
\text { produce progressive bed } \\
\text { subsurface fining. }\end{array}$ & & \\
\hline$\therefore$ : & $\begin{array}{l}\text { Congested bed (some runs } \\
\text { develop a pavement): } \\
\text { transport of coarse gravels, } \\
\text { finer gravels being quickly } \\
\text { stored in the bed }\end{array}$ & $\begin{array}{l}\text { Outlet solid discharge is } \\
\text { minimum and similar to } \\
\text { expected value with } \\
\text { transport of a uniform } \\
\text { sediment mixture. }\end{array}$ & $\begin{array}{l}\text { The gravel transport } \\
\text { rate efficiency is } \\
\text { minimum } \theta_{m}: \\
e_{m} S<\varphi\left(q_{s}, q\right)\end{array}$ \\
\hline ஃ。 & $\begin{array}{l}\text { Aggradation is not infinite } \\
\text { stops when the new en } \\
\text { slope } S_{M} \text { allows transpo } \\
\text { injected sediments }\end{array}$ & $\begin{array}{l}q_{s(\text { in) }}=q_{s(\text { out) }} \text { presence of } \\
\text { fine sediments in the } \\
\text { bedload layer increases } \\
\text { the coarse gravel mobility. }\end{array}$ & $\begin{array}{l}\varphi\left(q_{s^{\prime}} q\right) \text { but } \\
\text { transport rate } \\
\text { cy increase to } \\
m\end{array}$ \\
\hline 임 & $\begin{array}{l}\text { Increased gravel mobility and } \\
\text { strong local erosion } \\
\text { producing a bedload sheet. }\end{array}$ & $\begin{array}{l}\text { Peak solid discharge } \\
\text { associated with bedload } \\
\text { sheet migration. }\end{array}$ & $\begin{array}{l}\theta_{M} S_{M} \gg \varphi\left(q_{s}, q\right) \\
S \text { decreases until } \\
e_{M} S=\varphi\left(q_{s}, q\right) \text { is } \\
\text { verified }\end{array}$ \\
\hline$\therefore$ & $\begin{array}{l}\text { Gravel mobility is reduced } \\
\text { abruptly when a minimum } \\
\text { slope } S_{m} \text { is attained. In some } \\
\text { runs antidune waves } \\
\text { contribute to reducing this } \\
\text { mobility. }\end{array}$ & $\begin{array}{l}\text { Cells of immobile coarse } \\
\text { gravels stop the finer } \\
\text { gravel transport. The } \\
\text { outlet solid discharge } \\
\text { decreases abruptly. } \\
\text { Aggradation starts again. }\end{array}$ & $\begin{array}{l}\text { Abrupt transport rate } \\
\text { efficiency decrease } \\
e \ll<\theta_{M} \text {, } \\
e S_{m} \ll \varphi\left(q_{s^{\prime}} q\right) \text {. } \\
\text { New slope increase. }\end{array}$ \\
\hline
\end{tabular}

Figure 15. Sketch of periodical bed load sheet production.

tive of a natural channel because fluctuations produced by the changes in the bed would have influenced the bed response when used as a signal entrance. This type of feedback effect would not have existed in a feed system with an infinite flume. Consequently, neither of the two methods was perfectly adapted.

[32] However, some field observations are consistent with our flume experiments. Bed load sheets and associated bed load transport pulsations were observed in several field experiments [Dinehart, 1992; Kuhnle et al., 1989; Whiting et al., 1988]. In a field experiment, Gomez [1983] observed that progressive bed paving associated with reduced sediment transport was affected by local purges covering the entire active bed width in a patchy mobile carpet and responsible for bed load increases. This field result is very consistent with the mechanisms deduced from our flume observations.

[33] Other evidence of bed load sheet migration could be deduced from observations of river beds at rest, where long and low-relief bed forms are commonly observed over a

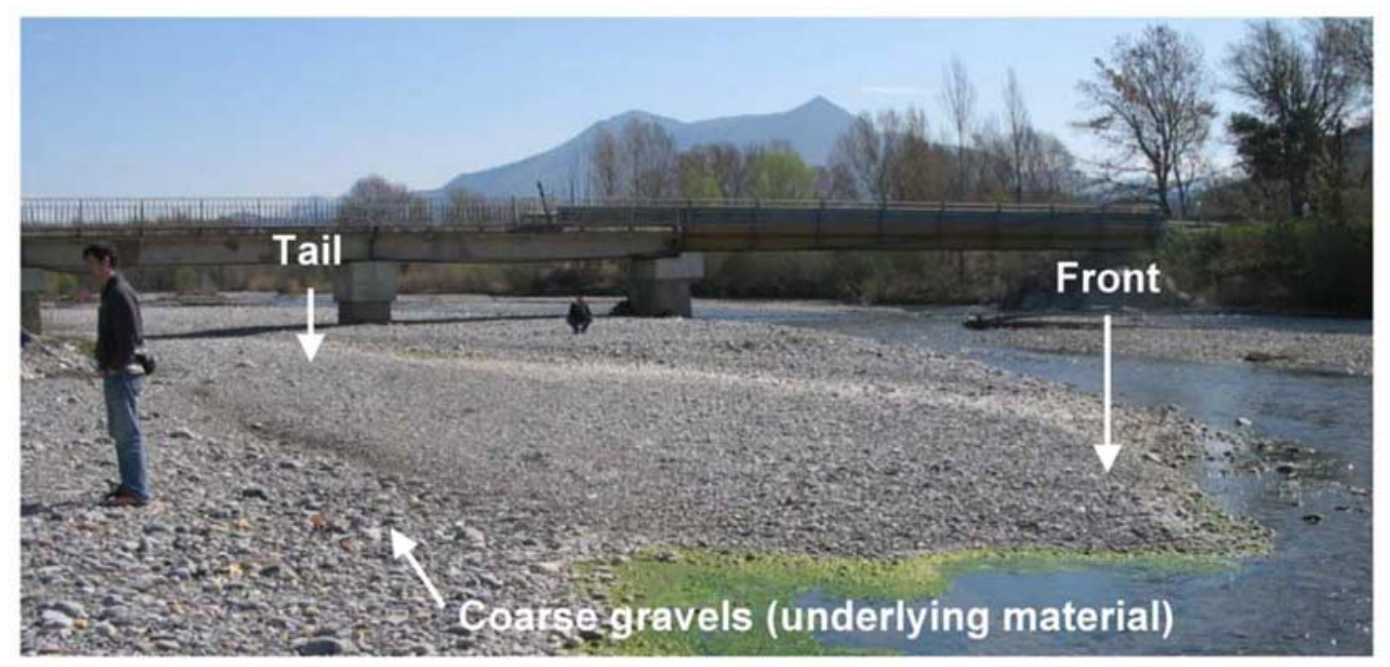

Figure 16. Low-relief bed form on the Bleone River (France) characterized by longitudinal grain sorting (coarser at the front) and a mean diameter smaller than the underlying material. 
layer of coarser sediments [Church and Jones, 1982]. This is illustrated in Figure 16 with an example on the Bleone River (France).

\section{Conclusion}

[34] Flume experiments were conducted for a wide range of flow conditions under dynamical equilibrium with poorly sorted materials, resulting in periodic bed load sheet production and migration every time the flow conditions verified $\theta<2 \theta_{c}$ (calculated for the coarser fraction of the sediment mixture). It was associated with periodic fluctuation of the mean and local bed slope, the bed state (fining and paving) and the associated bed load.

[35] The experimental results were compared with the results of experiments previously conducted by authors testing uniform sediments. For each run characterized by a sediment mixture of mean diameter $D$, the maximum slope for aggradation was equivalent to the slope that would have been obtained at equilibrium with a uniform sediment of the same diameter $D$. Fractional transport rates were measured with image analysis in one run. Comparison with transportation of uniform sediments at equilibrium allowed us to conclude that the peak solid discharge associated with bed load sheet migration was essentially attributable to the much higher mobility of coarse gravels when transported with finer gravels. However, the measurements also indicated that transportation of the finer gravels was sharply reduced by the presence of coarser gravels during bed coarsening and was not affected during transportation in the bed load sheet. Considering these results and the energy conservation equation, we interpret bed load sheets to be the consequence of a combined effect of grain sorting and the episodic increase in the transport rate efficiency of the coarser fraction of the sediment mixture.

[36] These experimental results contribute to a better understanding of the complexity of bed load transport, as time scale and space-scale effects observed in the flume were also identified in the field. We think that some spatial and temporal patterns observed in the field could be analyzed taking into account this research to enhance our geomorphological interpretation. Among other topics, this research should be of particular interest for bed load measurement and prediction. Concerning measurements, short-term fluctuations should be treated by averaging [Kuhnle, 1996] over a sufficiently long time (hours to days). However, currently, no clear criteria exist that can be used to identify a critical minimum duration to be considered (which is likely to depend both on the sediment mixture and the flow regime). This should be analyzed in future studies. As for bed load prediction, this study recalls the need to pursue research on bed load transport equations applicable for nonuniform sediments [Almedeij et al., 2006; Wilcock and Crowe, 2003; Wu et al., 2001].

[37] Acknowledgments. This study was supported by Cemagref and funding was provided by the ECCO-PNRH program from ANR/INSU ANR-05-ECCO-015. We are grateful to the TSI laboratory of Saint Etienne (Christophe Ducottet, Nathalie Bochard, Jacques Jay, and Jean-Paul Schon). The authors would like to thank Basil Gomez and two other anonymous reviewers who greatly contributed to this paper by providing helpful reviews of an earlier version of this manuscript. Our thanks are extended to Rob Ferguson (Associate Editor) who greatly contributed to this paper by providing additional reviews.

\section{References}

Almedeij, J. H., P. Diplas, and F. Al-Ruwaih (2006), Approach to separate sand from gravel for bed-load transport calculations in streams with bimodal sediment, J. Hydraul. Eng., 132, 1176-1185, doi:10.1061/ (ASCE)0733-9429(2006)132:11(1176).

Ancey, C., T. Bohm, M. Jodeau, and P. Frey (2006), Statistical description of sediment transport experiments, Phys. Rev. E, 74, 011302.1-011302.14.

Ancey, C., A. C. Davison, T. Bohm, M. Jodeau, and P. Frey (2008), Entrainment and motion of coarse particles in a shallow water stream down a steep slope, J. Fluid Mech., 595, 83-114, doi:10.1017/S0022112007008774.

Ashmore, P. E. (1988), Bedload transport in braided gravel bed stream models, Earth Surf. Processes Landforms, 13, 677-695, doi:10.1002/ esp.3290130803.

Ashmore, P. E. (1991), How do gravel-bed rivers braid?, Can. J. Earth Sci., $28,326-341$.

Bagnold, R. A. (1966), An approach to the sediment transport problem from general physics, Geol. Surv. Prof. Pap. 422-I, 37 pp., U. S. Dep. of Inter., Washington, D. C.

Bennett, S. J., and J. S. Bridge (1995), The geometry and dynamics of lowrelief bed forms in heterogeneous sediment in a laboratory channel, and their relationship to water flow and sediment transport, J. Sediment. Res., A65, 29-39.

Billi, P., V. Agostino, M. Lenzi, and L. Marchi (1998), Bedload, slope and channel processes in a high-altitude alpine torrent, in Gravel Bed Rivers in the Environment, pp. 15-38, chapter 3, edited by P. C. Klingeman et al., Water Resour., Highlands Ranch, Colo.

Blom, A., J. S. Ribberink, and H. J. De Vriend (2003), Vertical sorting in bed forms: Flume experiments with a natural and a trimodal sediment mixture, Water Resour. Res., 39(2), 1025, doi:10.1029/2001WR001088.

Blom, A., J. S. Ribberink, and G. Parker (2008), Vertical sorting and the morphodynamics of bed forms-dominated rivers: A sorting evolution model, J. Geophys. Res., 113, F01019, doi:10.1029/2006JF000618.

Böhm, T., P. Frey, C. Ducottet, C. Ancey, M. Jodeau, and J. L. Reboud (2006), Two-dimensional motion of a set of particles in a free surface flow with image processing, Exp. Fluids, 41, 1-11, doi:10.1007/ s00348-006-0134-9

Bridgwater, J. (1969), Paricle mixing by percolation, Trans. Inst. Chem. Eng., 47, 114-119.

Bunte, K. (1992), Particle number grain size composition of bedload in a mountain stream, in Dynamics of Gravel Bed Rivers, edited by R. D. H. P. Billi, C. R. Thorne, and P. Tacconi, pp. 55-68, John Wiley, Chichester, U. K. Church, M., and M. A. Hassan (1998), Stabilizing self-organized structures in gravel-bed stream channels: Field and experimental observations, Water Resour. Res., 34, 3169-3179, doi:10.1029/98WR00484.

Church, M., and D. Jones (1982), Channel bars in gravel-bed rivers, in Gravel-Bed Rivers, edited by R. D. Hey, pp. 291-338, John Wiley, Chichester, U. K.

Cudden, J. R., and T. B. Hoey (2003), The causes of bedload pulses in a gravel channel: The implications of bedload grain-size distribution, Earth Surf. Processes Landforms, 28, 1411-1428, doi:10.1002/esp.521.

Cui, Y., G. Parker, T. E. Lisle, J. Gott, M. E. Hansler, J. E. Pizzuto, N. E. Allmendinger, and J. M. Reed (2003), Sediment pulses in mountain rivers. Part 1: Experiments, Water Resour. Res., 39(9), 1240, doi:10.1029/2002WR001805.

Curran, C., and P. R. Wilcock (2005), Effects of sand supply on transport rates in a gravel-bed channel, J. Hydraul. Eng., 131, 961-967, doi:10.1061/(ASCE)0733-9429(2005)131:11(961).

Dietrich, W. E., J. W. Kirchner, H. Ikeda, and F. Iseya (1989), Sediment supply and the development of the coarse surface layer in gravel-bedded rivers, Nature, 340, 215-217.

Dinehart, R. L. (1989), Dune migration in steep coarse-bedded stream, Water Resour. Res., 25, 911-923, doi:10.1029/WR025i005p00911.

Dinehart, R. L. (1992), Evolution of coarse gravel bed forms: Field measurements at flood stage, Water Resour. Res., 28, 2667-2689, doi:10.1029/92WR01357.

Drahun, J. A., and J. Bridgwater (1983), The mechanism of free surface segregation, Powder Technol., 36, 39-53, doi:10.1016/0032-5910 (83)80007-2.

Ducottet, C. (1994), Application of wavelet transforms to the processing of tomographic and holographic images of fluid flows, Ph.D. thesis, Univ. of Saint Etienne, Saint Etienne, France.

Ehrenberger, R. (1931), Direct bedload measurements on the Danube at Vienna and their results to date, Wasserwirtschaft, 34, 1-9.

Einstein, H. A. (1937), The calibration of the bedload trap used in the Rhine, Schweiz. Bauztg., 110, 29-32.

Einstein, H. A. (1950), The bed-load function for sediment transportation in open channel flows, Tech. Bull. 1026, 71 pp., U. S. Dep. of Agric., Washington, D. C.

Emmett, W. W. (1975), The channels and waters of the upper Salmon River area, Idaho, Prof. Pap. 870 A, 113 pp., U. S. Geol. Surv., Reston, Va. 
Felix, G., and N. Thomas (2004), Evidence of two effects in the size segregation process in dry granular media, Phys. Rev. E, 70, 051307.1-051307.16.

Ferguson, R., K. L. Prestegaard, and P. J. Ashworth (1989), Influence of sand on gravel transport in a braided gravel bed river, Water Resour. Res., 25, 635-643, doi:10.1029/WR025i004p00635.

Frey, P., C. Ducottet, and J. Jay (2003a), Fluctuations of bed load solid discharge and grain size distribution on steep slopes with image analysis, Exp. Fluids, 35, 589-597, doi:10.1007/s00348-003-0707-9.

Frey, P., P. Ronco, and A. Recking (2003b), Fluctuations of bed load solid discharge and grain size distribution on steep slopes, paper presented at 2003 Symposium on River, Coastal, and Estuarine Morphodynamics, Int. Assoc. of Hydraul. Eng. and Res., Barcelona, Spain.

Garcia, C., J. B. Laronne, and M. Sala (2000), Continuous monitoring of bedload flux in a mountain gravel-bed river, Geomorphology, 34, 23-31, doi:10.1016/S0169-555X(99)00128-2.

Gilbert, G. K. (1914), The transportation of debris by running water, $U$. S. Geol. Surv. Prof. Pap. 86, 263 pp., Gov. Print. Off., Washington, D. C.

Gomez, B. (1983), Temporal variations in bedload transport rates: The effects of progressive bed armouring, Earth Surf. Processes Landforms, 8, 41-54, doi:10.1002/esp.3290080105.

Gomez, B., L. N. Richard, and D. W. Hubbell (1989), Temporal variations in bedload transport rates associated with the migration of bedforms, Earth Surf. Processes Landforms, 14, 135-156, doi:10.1002/esp. 3290140205.

Griffiths, G. A. (1979), Recent sedimentation history of the Waimakariri River, New Zealand, J. Hydrol., 18, 6-28.

Habersack, H., H. P. Nachtnebel, and J. B. Laronne (2001), The continuous measurement of bedload discharge in a large alpine gravel bed river, J. Hydraul. Res., 39, 125-133.

Hoey, T. B. (1992), Temporal variations in bedload transport rates and sediment storage in gravel-bed rivers, Prog. Phys. Geogr., 16, 319338, doi:10.1177/030913339201600303.

Hoey, T. B., and A. J. Sutherland (1991), Channel morphology and bedload pulses in braided rivers: A laboratory study, Earth Surf. Processes Landforms, 16, 447-462, doi:10.1002/esp.3290160506.

Hubbell, D. W. (1987), Bedload sampling and analysis, in Sediment Transport in Gravel-Beds Rivers, edited by C. R. Thorne, J. C. Bathurst, and R. D. Hey, pp. 89-106, John Wiley, Chichester, U. K.

Ikeda, H., and F. Iseya (1988), Experimental study of heterogeneous sediment transport, Environ. Res. Cent. Pap. 12, 50 pp., Univ. of Tsukuba, Tsukuba, Japan.

Iseya, F., and H. Ikeda (1987), Pulsations in bedload transport rates induced by a longitudinal sediment sorting: A flume study using sand and gravel mixture, Geogr. Ann., 69, 15-27, doi:10.2307/521363.

Jackson, W. L., and R. L. Beschta (1982), A model of two-phase bedload transport in an Oregon coast range stream, Earth Surf. Processes Landforms, 7, 517-527, doi:10.1002/esp.3290070602.

Jackson, W. L., and R. L. Beschta (1984), Influences of increased sand delivery on the morphology of sand and gravel channels, Water Resour. Bull., 20, 527-533.

Kang, S. (1982), Sediment transport in small glacial stream: Hilda Creek, Alberta, Ph.D. thesis, 265 pp., Univ. of Ill. at Chicago, Chicago, Ill.

Kuhnle, R. A. (1989), Bed-surface size changes in gravel-bed channel, J. Hydraul. Eng., 115, 731-743.

Kuhnle, R. A. (1996), Unsteady transport of sand and gravel mixtures, in Advances in Fluvial Dynamics and Stratigraphy, edited by P. C. A. M. Dawson, pp. 183-201, chapter 5, John Wiley, Chichester, U. K.

Kuhnle, R. A., and J. B. Southard (1988), Bed load transport fluctuations in a gravel bed laboratory channel, Water Resour. Res., 24(2), 247-260, doi:10.1029/WR024i002p00247.

Kuhnle, R. A., and J. B. Southard (1990), Flume experiments on the transport of heavy minerals in gravel-bed streams, J. Sediment. Petrol., 60, 687-696.

Kuhnle, R. A., J. C. Willis, and A. J. Bowie (1989), Variations in the transport of bedload sediment in a gravel-bed stream, Goodwin Creek, Mississippi, USA, paper presented at 4th International Symposium on River Sedimentation, U. N. Educ. Sci. and Cult. Organ., Beijing.

Lamb, M. P., W. E. Dietrich, and J.-G. Venditti (2008), Is the critical Shields stress for incipient sediment motion dependent on channel-bed slope?, J. Geophys. Res., 113, F02008, doi:10.1029/2007JF000831.

Lekach, J., and A. Schick (1983), Evidence for transport of bedload in waves: Analysis of fluvial sediment samples in a small upland stream channel, Catena, 10, 267-279.

Madej, M. A., and V. Ozaki (1996), Channel response to sediment wave propagation and movement, Redwood Creek, California, USA, Earth Surf. Processes Landforms, 21, 911-927, doi:10.1002/(SICI)10969837(199610)21:10<911::AID-ESP621>3.0.CO;2-1.
Meade, R. H. (1985), Wavelike movement of bedload sediment, East Fork River, Wyoming, Environ. Geol. Water Sci., 7, 215-225, doi:10.1007/ BF02509922.

Mühlofe (1933), Investigations into suspended load and bedload of the river Inn, near Kirchbichl, Tirol, Wasserwirtschaft, 7, 1-6.

Paige, A. D., and E. J. Hickin (2000), Annual bed-elevation regime in the alluvial channel of Squamish River, Southern British Columbia, Canada, Earth Surf. Processes Landforms, 25, 991-1009, doi:10.1002/10969837(200008)25:9<991::AID-ESP113>3.0.CO;2-W.

Parker, G. (1991), Some random notes on grain sorting, paper presented at Grain Sorting Seminar, Int. Assoc. of Hydraul. Eng. and Res., Ascona, Switzerland.

Parker, G., and P. R. Wilcock (1993), Sediment feed and recirculating flumes: Fundamental difference, J. Hydraul. Eng., 119, 1192-1204, doi:10.1061/(ASCE)0733-9429(1993)119:11(1192).

Raudkivi, A. J., and R. Ettema (1982), Stability of armour layers in rivers, J. Hydraul. Div. Am. Soc. Civ. Eng., 108, 1047-1057.

Recking, A. (2006), An experimental study of grain sorting effects on bedload, Ph.D. thesis, 261 pp., Cemagref, Lyon, France. (Available at www.lyon.cemagref.fr/doc/these/recking/index.shtml.)

Recking, A. (2009), Theoretical development on the effects of changing flow hydraulics on incipient bedload motion, Water Resour. Res., 45, W04401, doi:10.1029/2008WR006826.

Recking, A., P. Frey, A. Paquier, P. Belleudy, and J. Y. Champagne (2008a), Bedload transport flume experiments on steep slopes, J. Hydraul. Eng., 134, 1302-1310, doi:10.1061/(ASCE)0733-9429(2008)134:9(1302).

Recking, A., P. Frey, A. Paquier, P. Belleudy, and J. Y. Champagne (2008b), Feedback between bed load and flow resistance in gravel and cobble bed rivers, Water Resour. Res., 44, W05412, doi:10.1029/2007WR006219.

Reid, I., L. E. Frostick, and A. C. Brayshaw (1985), The incidence and nature of bedload transport during flood flows in coarse-grained alluvial channels, Earth Surf. Processes Landforms, 10, 33-44, doi:10.1002/ esp.3290100107.

Seminara, G., M. Colombini, and G. Parker (1996), Nearly pure sorting waves and formation of bedload sheet, J. Fluid Mech., 312, 253-278.

Song, T., W. H. Graf, and U. Lemmin (1995), Uniform flow in open channels with movable gravel bed, J. Hydraul. Res., 32, 861-875.

Suzuki, K., H. Yamamoto, and A. Kadota (1998), Mechanism of bedload fluctuations of sand-gravel mixture in a steep slope channel, paper presented at 11 th Congress, Int. Assoc. of Hydraul. Eng. and Res. Asia and Pac. Div., Yogyakarta, Indonesia.

Tacconi, P., and P. Billi (1987), Bedload transport masurements by the vortex-tube trap on Virginio Creek, Italy, in Sediment Transport in Gravel Bed Rivers, edited by C. R. Thorne, J. C. Bathurst, and R. D. Hey, pp. 583-606, John Wiley, Chichester, U. K.

Thomas, N. (2000), Reverse and intermediate segregation of large beads in dry granular media, Phys. Rev. E, 62, 961-974, doi:10.1103/ PhysRevE.62.961

Van den Berg, J. H. (1995), Prediction of alluvial channel pattern of perennial rivers, Geomorphology, 12, 259-279, doi:10.1016/0169-555X(95)00014-V. Whiting, P., W. E. Dietrich, L. B. Leopold, T. G. Drake, and R. L. Sherve (1988), Bedload sheets in heterogenous sediments, Geology, 16, 105-109, doi:10.1130/0091-7613(1988)016<0105:BSIHS >2.3.CO;2.

Wilcock, P. R. (1992), Experimental investigation of the effect of mixture properties on transport dynamics, in Dynamic of Gravel Bed Rivers, edited by P. Billi et al., pp. 109-131, John Willey, Chichester, U. K.

Wilcock, P. R., and J. C. Crowe (2003), Surface-based transport model for mixed-size sediment, J. Hydraul. Eng., 129, 120-128, doi:10.1061/ (ASCE)0733-9429(2003)129:2(120)

Wilcock, P. R., and B. W. McArdell (1993), Surface-based fractional transport rates: Mobilization thresholds and partial transport of a sand-gravel sediment, Water Resour. Res., 29, 1297-1312, doi:10.1029/92WR02748.

Wilcock, P. R., S. T. Kenworthy, and J. C. Crowe (2001), Experimental study of the transport of mixed sand and gravel, Water Resour. Res., 37 , 3349-3358, doi:10.1029/2001WR000683.

Wu, W., S.-Y. Wang, and Y. Jia (2001), Non-uniform sediment transport in alluvial rivers, J. Hydraul. Res., 38, 427-434.

P. Belleudy, Laboratoire d'Étude des Transferts en Hydrologie et Environnement, UMR5564, CNRS, BP 53, F-38041 Grenoble CEDEX 9, France. (philippe.belleudy@hmg.inpg.fr)

P. Frey and A. Recking, UR Erosion Torrentielle Neige Avalanches, Cemagref, 2 Rue de la Papeterie, BP 76, F-38402 Saint Martin d'Hères, France. (philippe.frey@cemagref.fr; alain.recking@cemagref.fr)

A. Paquier, Hydrology Hydraulics Unit, Cemagref, Quai Chauveau, 3 Bis, CP 220, F-69336 Lyon CEDEX 09, France. (andre.paquier@cemagref.fr) 